\title{
sciendo
}

\section{The Transition from Underwater to Surface Swimming During the Push-off Start in Competitive Swimmers}

\author{
by \\ Alfonso Trinidad ${ }^{1}$, Santiago Veiga ${ }^{2}$ Enrique Navarro ${ }^{2}$, Alberto Lorenzo ${ }^{3}$
}

The objective of the present study was to analyze (based on gender and the style of swimming) the kinematic parameters of the transition phase between underwater swimming and surface swimming after the push-off start in competitive national swimmers. Seventy-four swimmers participating in the Spanish Swimming Championships were filmed and analyzed by DLT-2D photogrammetry during the start with the push-off in crawl, backstroke and butterfly styles. Between genders there were small differences in the distance and speed of transition. The male swimmers travelled greater distances $(0.84 \pm 0.04$ vs. $0.66 \pm 0.04 m, \eta 2=0.05, F=10.34, p<0.001)$ and they were faster $(1.59 \pm$ 0.03 vs. $1.38 \pm 0.03 \mathrm{~m} / \mathrm{s}, \eta 2=0.08, F=19.54, p<0.001)$ in the transition phase than female swimmers. Among styles there were greater differences in time $(\eta 2=0.47, F=94.50, p<0.001)$ and transition distance $(\eta 2=0.38, F=67.08, p<$ 0.001 ), than in speed ( $\eta 2=0.05, F=5.63, p<0.001)$. During the backstroke push-off, swimmers spent more time $(0.88$ $\pm 0.04 \mathrm{~s})$ and distance $(1.17 \pm 0.05 \mathrm{~m})$, this being the slowest style $(1.37 \pm 0.04 \mathrm{~m} / \mathrm{s})$. In butterfly, athletes used less time $(0.26 \pm 0.03 \mathrm{~s})$ and distance $(0.39 \pm 0.05 \mathrm{~m})$ whereas crawl was the fastest of all $(1.57 \pm 0.04 \mathrm{~m} / \mathrm{s})$. These results allow the phase of transition from underwater to surface swimming to be characterized and to provide useful data for competitive swimmers and coaches to improve performance.

Key words: biomechanics, kinematics, performance, direct linear transformation, 2D.

\section{Introduction}

The underwater swim that takes place in swimming in the start and turn phases has been one of the most studied parts to improve performance of swimmers. The higher speed of swimmers during this phase compared to surface swimming (Marinho et al., 2009; Tor et al., 2014) as well as the need to adjust underwater distances to the maximum $15 \mathrm{~m}$ rule (FINA, 2009), makes many researchers try to decipher how this part of the race can enhance performance (Fischer and Kibele, 2016). Previous studies in competition have already shown that performance in the start and turn phases have a key influence on the swimming race outcome (Veiga et al., 2014a, b).

The first phase that occurs in the underwater swim is the gliding phase (Figure 1). Concerning that phase, the positions of the fully extended arms in the front seem to substantially reduce the negative hydrodynamic effects of the morphology of the human body (Marinho et al., 2011). It should not be forgotten that there is a strong relationship between total passive drag force and the resistance coefficient measured by computational fluid dynamics (CFD) according to Barbosa et al. (2018). Once the swimmer decreases its forward speed to about 1.75 to $2.0 \mathrm{~m} / \mathrm{s}$ (Li et al., 2017) (from 3-3.5 m/s in which the wall push off is performed) then he/she must finalize the gliding phase and begin with the underwater propulsion phase, in order to reduce the swimmer's

1 - Facultad de Educación y Humanidades, Francisco de Vitoria Universidad, Pozuelo de Alarcón-Madrid, Spain.

2 - Departamento de Salud y Rendimiento Humano, Universidad Politécnica de Madrid, Spain.

3 - Departamento de Deportes, Universidad Politécnica de Madrid, Spain. 
deceleration (Naemi and Sanders, 2008; Takeda et al., 2009; Vantorre et al., 2010a, b, c).

In the underwater propulsion phase, swimmers move their feet simultaneously vertically (Von Loebbecke et al., 2009), in a wave motion (Connaboy et al., 2009). The effectiveness of this phase is related to the frequency (Cohen et al., 2012), the amplitude of the kick (Houel et al., 2013), the propulsive symmetry (Atkinson et al., 2013), muscle power and hydrodynamic position (Lyttle et al., 2000). The distances reached by the swimmers with underwater propulsion (around $12-13 \mathrm{~m}$ for the start and around $8-10 \mathrm{~m}$ for the turn) have been related to the performance of start and turns in different races and styles (TournyChollet et al., 2002; Veiga et al., 2014a, b).

Once the swimmer finishes the wave underwater propulsion, he/she must continue with the propulsion of the alternate kick (crawl and backstroke) or begin with the propulsion of the arms (crawl, backstroke and butterfly), while the head breaks the surface of the water. This phase, called breakout or transition between the underwater swim and the surface swim (Navandar et al., 2016). The main objective of this phase for the swimmer is to avoid a loss of speed and start the surface swim, benefiting from the previous inertia of the underwater swim (Veiga and Roig, 2016). For this reason, the swimmer must adapt his/her cyclic swimming parameters (frequency and cycle length) to the speed in which the surface swim will begin (Chollet et al., 2006, 2008; Seifert et al., 2004, 2007; Sweetenham and Atkinson, 2003). On the other hand, another study conducted with national-level swimmers (Navandar et al., 2016) detected differences in the speed of the transition between the different styles (crawl: $1.72 \mathrm{~m} / \mathrm{s}$, backstroke: $1.63 \mathrm{~m} / \mathrm{s}$, butterfly: $1.68 \mathrm{~m} / \mathrm{s}$ ), with values higher than those of the free swim (crawl: $1.61 \mathrm{~m} / \mathrm{s}$, backstroke: $1.34 \mathrm{~m} / \mathrm{s}$, butterfly: $1.47 \mathrm{~m} / \mathrm{s})$. However, there are no other precedents in the literature that describe what happens during a phase that could be of great importance for swimming performance.

Therefore, in the present study the objective was to analyse (based on gender and the style of swimming) the kinematic parameters of the transition phase between underwater swimming and surface swimming after the pushoff, in competitive swimmers of a national level. It was hypothesized that the stroking parameters during the breakout would depend on the swimming stroke and also on gender.

\section{Methods}

\section{Participants}

A total of 74 swimmers, 33 males (16.5 \pm 1.29 years and $62.34 \pm 7.22 \mathrm{~kg}$ ) and 41 females $(15.5 \pm 1.29$ years and $50.50 \pm 6.53 \mathrm{~kg})$ participating in the Spanish Championships and belonging to eight clubs of the Madrid Swimming Federation, in the national-junior category, took part voluntarily in the study, with the informed signed consent of their parents or guardians. Swimmers in this study followed a training regime between 12 and 20 hours per week in the water. The trial was conducted in the middle lane of the $50 \times 25 \mathrm{~m}$ indoor pool of the "M-86" Competitive Swimming Technique Specialist Center of the Madrid Autonomous Region.

\section{Instruments}

The swimmers were filmed using two JVC GY-DV500E video cameras (located in the lateral underwater windows of the pool) recording at $25 \mathrm{Hzand}$. The distance between the lenses of these cameras and the swimmers was approximately $12.5 \mathrm{~m}$. Using DLT-2D algorithms (Abdel-Aziz and Karara, 1971), the real coordinates $(x, y)$ were calculated from the digitalized pixel coordinates on the computer screen (Photo23D, Polytechnic University of Madrid, Spain) (Cala et al., 2009). A calibration frame formed by four points of known coordinates in a vertical plane in the swimming lane was employed for the coordinate's calculation. The mechanical model used to determine the position of the swimmer was that of a point represented by the swimmer's hip (Fernandes et al., 2012) from which the coordinates $(x, y)$ and the variables of the study were obtained.

\section{Design and procedures}

Participants were filmed individually underwater in three trials (butterfly, backstroke and crawl styles in random order) from the wall push-off to the $15 \mathrm{~m}$ mark at maximum swimming velocity, with a free underwater swimming period in which only the transition phase from underwater to the surface was analyzed. The transition phase started when the swimmer broke the position of the dolphin kick with the separation of arms (or feet) and it 
finished when the swimmer's head broke the water surface to later initiate the first arm recovery. In the crawl and backstroke styles, this took place when the legs or one of the arms were separated, thus breaking the position of minimum resistance (Figure 2). On the other hand, in the butterfly style it only started with the separation of the two arms. Once the coordinates $(x, y)$ of the positions of athletes were obtained in each time interval, the following variables could be obtained: time (TTR), distance (DTR) and velocity (VTR) during the transition phase to the surface swim.

\section{Statistical analysis}

The statistical analysis of the data was carried out using SPSS version 15.0 (SPSS Inc., Chicago, IL, USA), the means and standard deviations being calculated for each of the kinematic variables (time, distance and velocity). Subsequently, an analysis of variance was performed with repeated measures with an intersubject factor (gender) and an intra-subject factor (style). The value of the contrast $\mathrm{F}$ was used together with the degrees of freedom for the statistical probability of the effects of a factor on the variance of the population. The level of significance ( $p$-value) was 0.05 . Finally, the results were interpreted by the effect size with the values of eta-squared $\left(\eta^{2}\right)$, according to the thresholds that represented small, moderate, large, very large and almost perfect correlations, which were 0.1,
$0.3,0.5,0.7$ and 0.9 respectively (Hopkins et al., 2009).

\section{Results}

The first observational analysis of video footage in the present research (Table 1) indicated that both freestyle and backstroke swimmers began their transition phase with hand separation (67.8\%) compared to feet separation (32.2\%).

Comparing genders, men traveled more distance during the transition than women $\left(\eta^{2}=\right.$ $0.05, F=10.34, p<0.001)$, but with a greater speed $\left(\eta^{2}=0.08, F=19.54, p<0.001\right)$. Despite this, significant differences were not found in time $\left(\eta^{2}=\right.$ $0.01, F=1.63, p<0.20$ ). The descriptive values and the multivariate analysis of each group are presented in Table 2.

Comparing styles, there were greater differences in time $\left(\eta^{2}=0.47, F=94.50, p<0.001\right)$ and transition distance $\left(\eta^{2}=0.38, F=67.08, p<\right.$ $0.001)$, than in the velocity $\left(\eta^{2}=0.05, F=5.63, p<\right.$ 0.001). During the backstroke exit, participants spent more time $(0.88 \pm 0.04 \mathrm{~s})$ and distance $(1.17 \pm$ $0.05 \mathrm{~m})$, the style being the slowest $(1.37 \pm 0.04$ $\mathrm{m} / \mathrm{s})$. In contrast, in the butterfly style, participants spent less time $(0.26 \pm 0.03 \mathrm{~s})$ and distance $(0.39 \pm 0.05 \mathrm{~m})$. However, crawl was the fastest $(1.57 \pm 0.04 \mathrm{~m} / \mathrm{s})$ (Table 3).

\begin{tabular}{|c|c|c|c|c|}
\hline & & & \multicolumn{2}{|c|}{ SWIM ON THE SURFACE } \\
\hline $\begin{array}{l}\text { - UNDERWATER } \\
\text { GLIDING }\end{array}$ & $\begin{array}{l}\text { UNDERWATER UNDULATORY } \\
\text { SWIMMING }\end{array}$ & $\begin{array}{r}\mathrm{T} \\
\text { T0 } 1\end{array}$ & $\begin{array}{l}\text { RANSITION } \\
\text { rHE SURFACE }\end{array}$ & $\begin{array}{l}\text { Crawl } \\
\text { Backstroke }\end{array}$ \\
\hline $\begin{array}{l}\text { UNDERWATER } \\
\text { GLIDING }\end{array}$ & UNDERWATER UNDULATORY SV & [MING] & $\begin{array}{c}\text { TRANSITION } \\
\text { TO THE SURFACE }\end{array}$ & Butterfly \\
\hline
\end{tabular}

Figure 1

Differentiated scheme of the phases during the underwater swim and the transition to the water surface. 


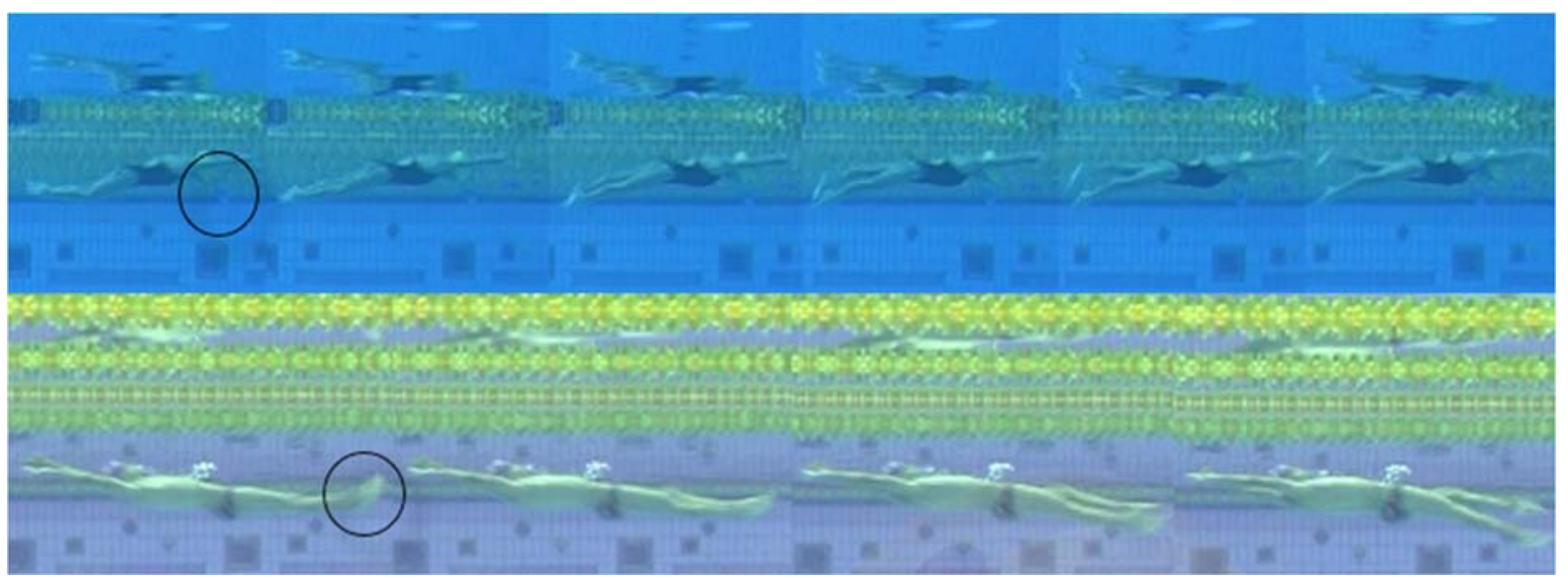

Figure 2

Beginning of the transition phase to the surface swim in the crawl and backstroke strokes.

Table 1

Percentage (\%) of the different types of beginning the transition phase in competitive swimmers.

\begin{tabular}{cccccc} 
& Beginning of & \multicolumn{2}{c}{ Style } & \multicolumn{2}{c}{ Gender } \\
& the transition & Crawl & Backstroke & Male & Female \\
\cline { 2 - 6 } Separation of the hands & $67.8 \%$ & $49.42 \%$ & $18.39 \%$ & $26.43 \%$ & $41.37 \%$ \\
Separation of the feet & $32.2 \%$ & $21.83 \%$ & $10.34 \%$ & $16.09 \%$ & $16.09 \%$ \\
\hline
\end{tabular}

Table 2

Descriptive results and multivariate analysis of kinematic parameters (by stroke) transition time

(TTR), transition distance (DTR) and transition speed (VTR) in swimmers of a national competitive level.

\begin{tabular}{ccccccccc}
\hline & Male & Female & $\begin{array}{c}\text { Sum of } \\
\text { squares }\end{array}$ & gl & $\begin{array}{c}\text { Half } \\
\text { quadratic }\end{array}$ & F & Sig. & $\eta^{2}$ \\
\cline { 2 - 9 } $\operatorname{TTR}(\mathrm{s})$ & $0.57 \pm 0.03$ & $0.51 \pm 0.03$ & 0.25 & 1 & 0.25 & 1.63 & 0.20 & 0.01 \\
$\operatorname{DTR}(\mathrm{m})$ & $0.57 \pm 0.03$ & $0.66 \pm 0.04$ & 2.77 & 1 & 2.77 & 10.34 & $0.00^{*}$ & 0.05 \\
$\operatorname{VTR}(\mathrm{m} / \mathrm{s})$ & $1.59 \pm 0.03$ & $0.66 \pm 0.04$ & 2.56 & 1 & 2.56 & 19.54 & $0.00^{*}$ & 0.08 \\
\hline \multicolumn{7}{c}{${ }^{*}$ Significant differences $(p<0.05)}$. & &
\end{tabular}

Table 3

Descriptive results and multivariate analysis of kinematic parameters (by stroke), transition time (TTR), transition distance (DTR) and transition speed (VTR) in national competitive level swimmers.

\begin{tabular}{cccccccccc}
\hline & Crawl & Backstroke & Butterfly & $\begin{array}{c}\text { Sum of } \\
\text { squares }\end{array}$ & gl & $\begin{array}{c}\text { Half } \\
\text { quadratic }\end{array}$ & F & Sig. & $\eta^{2}$ \\
\cline { 2 - 9 } TTR (s) & $0.47 \pm 0.03$ & $0.88 \pm 0.04$ & $0.26 \pm 0.03$ & 15.49 & 2 & 7.75 & 94.5 & $0.00^{*}$ & 0.47 \\
$\operatorname{DTR}(\mathrm{m})$ & $0.74 \pm 0.05$ & $1.17 \pm 0.05$ & $0.39 \pm 0.05$ & 23.31 & 2 & 11.65 & 67.08 & $0.00^{*}$ & 0.38 \\
$\operatorname{VTR}(\mathrm{m} / \mathrm{s})$ & $1.57 \pm 0.04$ & $1.37 \pm 0.04$ & $1.52 \pm 0.04$ & 1.53 & 2 & 0.77 & 5.63 & $0.00^{*}$ & 0.05 \\
\hline
\end{tabular}

${ }^{*}$ Significant differences $(p<0.05)$. 


\section{Discussion}

The start and turn phases in swimming are a part of the race with an important impact on the performance of both male and female swimmers. However, not all sub-phases that compose them have been extensively analyzed (Atkinson et al., 2013; Lyttle et al., 2000; Takeda et al., 2009). In the present study, the kinematic parameters of the transition phase between underwater swimming and surface swimming after the push-off were analyzed in competitive national swimmers (according to gender and style of swimming).

Our results indicate gender differences in the kinematic parameters of the transition, consequently, the time was very close between both genders $(0.57 \pm 0.03$ and $0.51 \pm 0.03 \mathrm{~s})$, although it was relatively longer in men (0.07 s) compared to women $(7.6 \%)$ from the wall pushoff to the surface exit. The men travelled almost 20 $\mathrm{cm}$ longer than women $(0.84 \pm 0.04$ and $0.66 \pm 0.04$ $\mathrm{m})$, while speed $(1.59 \pm 0.03$ vs. $1.38 \pm 0.03 \mathrm{~m} / \mathrm{s})$ showed $13.2 \%$ faster values in men. These differences according to Vantorre et al. (2010a, c), could be related to a greater muscular power of legs or a more hydrodynamic position in men (Barbosa et al., 2018; Houel et al., 2013; Marinho et al., 2011; Von Loebbecke et al., 2009). However, since other research has analyzed the underwater phase without taking into account the transition phase from diving to swimming (Fischer and Kibele, 2016; Vantorre et al., 2010a, b, c), it is impossible to contrast our findings.

In terms of the style, there were significant differences between the kinematic parameters of the butterfly, backstroke and crawl transition. Butterfly was the one with less time and distance travelled of all $(0.26 \mathrm{~s}$ and $0.39 \mathrm{~m})$, compared with crawl $(0.47 \pm 0.03 \mathrm{~s}$ and $0.74 \pm 0.05$ $\mathrm{m})$ and backstroke $(0.88 \pm 0.04 \mathrm{~s}$ and $1.17 \pm 0.05 \mathrm{~m})$ from the wall push to the water surface. These differences are related to the different segmental coordination (alternative or simultaneous) between strokes, since the exit of the head in butterfly occurred just after separating the hands. This caused a shorter time and distance of transition to the surface, causing the position of minimum resistance to break early (Marinho et al., 2009) after the underwater kicking and confirming the importance of a proper coordination between arms and legs (Chollet et al., 2006). However, in the alternative strokes (freestyle and backstroke), swimmers may initially separate the hands or feet before breaking the water surface to maintain forward speed during the first two strokes (Sweetenham and Atkinson, 2003). Observational analysis from the present research indicated that, interestingly, both freestyle and backstroke swimmers began the transition with hand separation $(67.8 \%)$ in a great proportion compared to feet separation (32.2\%). In relation to a study of Navandar et al. (2016), the arm recovery phase could also explain some of the differences found between the strokes during the transition, since the first propulsive phase of the butterfly kicking was greater than the second and this could help coordinate the beginning of the action of arms (Chollet et al., 2006; Navandar et al., 2016; Seifert et al., 2007) for the transition to the surface.

As for the transition speed, the backstroke stroke was the slowest $(1.37 \pm 0.04 \mathrm{~m} / \mathrm{s})$ compared to butterfly $(1.52 \pm 0.04 \mathrm{~m} / \mathrm{s})$ and crawl $(1.57 \pm 0.04$ $\mathrm{m} / \mathrm{s})$. These values coincide in the order between strokes (Crawl> Butterfly> Backstroke) shown by Navandar et al. (2016). On the other hand, they were similar to those presented by Seifert et al. (2004) in crawl $(1.61 \mathrm{~m} / \mathrm{s})$, Chollet et al. (2008) in backstroke $(1.34 \mathrm{~m} / \mathrm{s})$ and Chollet et al. (2006) and Seifert et al. (2007) in butterfly $(1.47 \mathrm{~m} / \mathrm{s})$, although these authors considered transition to the end of the first stroke cycle. Interestingly, backstroke was the slowest stroke compared to other studies (Chollet et al., 2008; Navandar et al., 2016) which could be related to a greater time and distance from the push off to the end of the underwater kicking or to an excessive early beginning of the kicking action after gliding (Li et al., 2017). It should also be noted that the underwater trajectory and depth (Naemi and Sanders, 2008; Vantorre et al., 2010a, b, c) could affect the subsequent transition to surface as, if inadequately performed, it could slow down swimmers before the stroking resumption.

These results indicate that coaches should include the transition drills in their training programs attending to the gender and stroke differences observed in the present research. Coaches should be aware that swimmers could travel different distances and spend different times during transition depending on the stroke, but aiming at maximizing forward 
velocity in all of them. Of course, these results should be interpreted considering that, in the present research, the underwater depth of the swimmers was not controlled, and this could have influenced the kinematic parameters obtained. In addition, it is proposed that future research could analyze the coordinative parameters, as we believe that these variables might explain the differences between strokes.

\section{Conclusions}

The kinematic study of the transition from underwater to surface swimming revealed that male swimmers traveled almost $20 \mathrm{~cm}$ further and were $0.21 \mathrm{~m} / \mathrm{s}$ faster, but in less time $(0.07 \mathrm{~s})$ than female swimmers. In swimmers at a national level, the transition phase was much faster in crawl and butterfly $(12.7 \%$ and $9.9 \%)$ than in the backstroke stroke, in spite of the differences in distance $(-0.35 \mathrm{~m}$ and $-0.78 \mathrm{~m})$. These results allow the phase of transition after the wall push-off to be characterized, since it has been a phase little studied in the literature, and to provide useful information for improving performance in competitive swimmers.

\section{References}

Abdel-Aziz YI, Karara HM. Direct linear transformation from comparator coordinates into space coordinates in close range photogrammetry. In American Society of Photogrammetry (Ed.), Proceedings of the symposium on close range photogrammetry. EE.UU: Falls-Church, 1-18; 1971

Atkison R, Dickey J, Dragunas A, Nolte V. Importance of sagittal kick symmetry for underwater dolphin kick performance. Hum Mov Sci, 2103; 33: 298-311

Barbosa TM, Ramos R, Silva AJ, Marinho DA. Assessment of passive drag in swimming by numerical simulation and analytical procedure. J Sports Sci, 2018; 36(5): 492-498

Cala A, Veiga S, García A, Navarro E. Previous cycling does not affect running efficiency during a triathlon World Cup competition. J Sports Med Phys Fitness, 2009; 49: 152-158

Chollet D, Carter M, Seifert L. Effect of technical mistakes on arm coordination in backstroke. Rev Port Cien Desp, 2006; 6 (Supl 2): 15-113

Chollet D, Charlies S, Chatard J. A New Index of Coordination fo the Crawl: Description and Usefulness. Inter J Sports Med, 2000; 21(1): 54-59

Chollet D, Seifert L, Carter M. Arm coordination in elite backstroke swimmers. J Sports Sci, 2008; 26(7): 675682

Costill DL, Maglischo EW, Richardson AB. Swimming. London, England: Blackwell Scientific Publications, 1992

Fernandes RJ, Ribeiro J, Figueiredo P, Seifert L, Vilas-Boas JP. Kinematics of the hip and body center of mass in front crawl. J Hum Kinet, 2012; 33: 15-23

FINA. FINA Swimming Rules 2009-2013. Fédération Internationale de Natation, 2009

Fischer S, Kibele A. The biomechanical structure of swim start performance. Sports Biomech, 2016; 15(4): 397408

Guimarães A, Hay J. A mechanical analysis of the grab starting technique in swimming. Int J Sport Biomech, 1985; 1: 25-35

Hopkins WG, Marshall SW, Batterham AM, Hanin J. Progressive statistics for studies in sports medicine and exercise science. Med Sci Sports Exerc, 2009; 41: 3-12

Houel N, Elipot M, Andrée F, Hellard P. Influence of angles of attack, frequency and kick longitude on swimmer's horizontal velocity during underwater phase of a grab start. J Appl Biomech, 2013; 29(1): 4954

Li T, Cai W, Zhan J. Numerical Investigation of Swimmer's Gliding Stage with 6-DOF Movement. PLoS ONE, 2017; 12(1): e0170894

Lyttle AD, Blanksby BA, Elliot BC, Lloyd DG. Net forces during tethered simulation of underwater streamlined gliding and kicking techniques of the freestyle turn. J Sports Sci, 200; 18: 801-807 
Maglischo EW. Swimming fastest. Champaign: Human Kinetics, 2003

Marinho DA, Rouboa AI, Alves FB, Vilas-Boas JP, Machado L, Reis VM, Silva AJ. Hydrodynamic analysis of different thumb positions in swimming. J Sports Sci Med, 2009; 8: 58-66

Marinho DA, Barbosa TM, Rouboa AI, Silva AJ. The Hydrodynamic Study of the Swimming Gliding: a TwoDimensional Computational Fluid Dynamics (CFD) Analysis. J Hum Kinet, 2011; 29: 49-57

Naemi R, Sanders RH. A "hydro-kinematic" method of measuring glide efficiency of a human swimmer. J Biomech Eng, 2008; 130 (6): 061016-061016-9

Navandar A, Veiga S, García I, Navarro E. Analysis of stroke, coordinative and temporal parameters in transition from underwater to surface swimming. 34rd International Conference of Biomechanics in Sport, 2016: 871-874. Tsukuba, Japan

Novais M, Silva A, Mantha V, Ramos R, Rouboa A, Vilas-Boas J, Luís S, Marinho D. The Effect of Depth on Drag During the Streamlined Glide: A Three-Dimensional CFD Analysis. J Hum Kinet, 2012; 33: 55-62

Pease D, Vennell R. The effect of angle of attack and depth on passive drag. In: Kjendlie P.L., Stallman R.K., \& Cabri J, editors. Biomechanics and Medicine in Swimming, 2010; XI: 145-147. Oslo: Norwegian School of Sport Sciences

Sanders RH. New analysis procedures for giving feedback to swimming coaches and swimmers. XXth International Symposium on Biomechanics in Sports-Swimming, 2002: 1-14. Caceres: University of Extremedura

Seifert L, Chollet D. A new index of flat breaststroke propulsion: A comparison of elite men and women. J Sports Sci, 2005; 23(3): 309-320

Seifert L, Delignieres D, Boulesteix L, Didier C. Effect of expertise on butterfly stroke coordination. J Sports Sci, 2007; 25(2): 131-141

Sweetenhham B, Atkinson J. Champioship swim training. Human Kinetics, 2003

Takeda T, Ichikawa H, Takagi H, Tsubakimoto S. Do differences in initial velocity persist to the stroke phase in front-crawl swimming? J Sports Sci, 2009; 27: 1449-1454

Vantorre J, Seifert L, Fernandes R, Vilas-Boas J, Chollet D. Biomechanical influence of start technique preference for elite track starters in front crawl. Open Sports Sci J, 2010a; 3: 137-139

Vantorre J, Seifert L, Fernandes RJ, Vilas-Boas J, Chollet D. Comparison of grab start between elite and trained swimmers. Int J Sports Med, 2010b; 31: 887-893

Vantorre J, Seifert L, Fernandes R, Vilas-Boas J, Chollet D. Kinematical profiling of the front crawl start. Int J Sports Med, 2010c; 31: 16-21

Veiga S, Roig A. Effect of the starting and turning performances on the subsequent swimming parameters of elite swimmers. Sports Biomech, 2016; 31: 1-11

Veiga S, Cala A, Frutos PG, Navarro E. Comparison of starts and turns of national and regional level swimmers by individualized distance measurements. Sports Biomech, 2014a; 13(3): 285-295

Veiga S, Mallo J, Navandar A, Navarro E. Effects of different swimming race constraints on turning movements. Hum Mov Sci, 2014b; 36: 217-226

Von Loebbecke A, Mittal R, Fish F, Mark R. Propulsive efficiency of the underwater dolphin kick in humans. J Biomech Eng, 2009; 131(5): 054504

\section{Corresponding author:}

\section{Alfonso Trinidad Morales}

Faculty of Education and Humanities, Francisco de Vitoria University (UFV). Ctra. M-515 Pozuelo-

Majadahonda km 1,800, 28223. Pozuelo de Alarcón, Madrid, Spain.

Phone and Fax: +34 917091400.

E-mail: alfonso.trinidad@ufv.es. 